\title{
Magneto-optic Contact for Application in an Amplifying Waveguide Optical Isolator
}

\author{
Wouter Van Parys, Dries Van Thourhout and Roel Baets \\ Department of Information Technology, Ghent University - IMEC, St-Pietersnieuwstraat 41, 9000 Gent, Belgium \\ wouter.vanparys@intec.ugent.be \\ Mathias Vanwolleghem \\ Institut d'Electronique Fondamentale, Université Paris-Sud, Bâtiment 220, 91405 Orsay Cedex, France \\ Bruno Thedrez and Francois Lelarge \\ Alcatel Thales III-V Lab, Route Départementale 128, 91767 Palaiseau, France \\ Roel Wirix-Speetjens and Liesbet Lagae \\ Interuniversitair Micro-Elektronica Centrum IMEC vzw, Kapeldreef 75, 3001 Leuven, Belgium
}

\begin{abstract}
We present the development of a metal-semiconductor contact for a TM-mode amplifying waveguide optical isolator and show that it is a compromise between good (magneto-)optical performance and good electrical behavior.
\end{abstract}

An optical isolator is indispensable in a telecom link to protect the laser sources against back-reflected light. A waveguide version of this component is highly desirable as it would decrease the packaging cost - hence the overall cost - of a laser diode module largely. An approach that is getting a lot of attention in recent years [1-2] involves the use of a ferromagnetic metal as the source of the non-reciprocal effect. In an optical waveguide covered with a transversely magnetized ferromagnetic metal film close to the guiding region, the magneto-optic (MO) Kerr effect induces a non-reciprocal shift of the complex effective index of the guided mode. In other words, the modal loss is dependent on the propagation direction of the light. If the guiding core consists of amplifying layers, electrical biasing decreases the internal loss of the waveguide. The result is a device which, being transparent in the forward while providing loss in the opposite direction, is isolating. As the isolator basically has the same structure as the laser it is to be integrated with, monolithic integration is straightforward. In the simplest configuration, illustrated in figure 1 and operating for TM-polarized light, the ferromagnetic metal acts as the electrical contact for the underlying semiconductor optical amplifier. Therefore, an important issue that needs to be solved is the development of an ohmic electrical contact for application in this optical isolator. In this paper we show that a compromise needs to be made between good optical and $\mathrm{MO}$ performance and good electrical behavior.

A metal-semiconductor contact is said to be ohmic if the contact does not influence the contacted device, that is if the contact resistivity is small (order $10^{-5} \Omega \mathrm{cm}^{2}$ ). The contact resistivity decreases with increasing dopant levels of the semiconductor layer in contact with the metal and with decreasing barrier height between metal and semiconductor. Due to pinning of the Fermi-level in III-V semiconductors the barrier height is quasi-independent of the workfunction of the metal, hence the unusual choice of the contact metal - a ferromagnetic metal - is not expected to deteriorate the contact quality. Furthermore, the barrier height decreases with diminishing bandgap energy of the semiconductor layer. The material lattice-matched to InP with the lowest bandgap is $\operatorname{In}_{0.53} \mathrm{Ga}_{0.47} \mathrm{As}$, hence the standard electrical contact of an amplifying device is composed of a highly doped $\operatorname{In}_{0.53} \mathrm{Ga}_{0.47} \mathrm{As}$ layer between the cladding and the metal. For the amplifying waveguide isolator the situation is more complicated. As the isolator performance is determined by the overlap of the guided mode with the ferromagnetic metal, it is fundamental that the semiconductor contact structure is transparent or at least little absorbing. At the operation wavelength of $1300 \mathrm{~nm}$, the absorption level of $\mathrm{In}_{0.53} \mathrm{Ga}_{0.47} \mathrm{As}$ equals $1.55 \times 10^{4} \mathrm{~cm}^{-1}$, making a standard contact structure not suitable for the isolator. We have examined four alternative contact structures (table 1), using a standard contact as the reference.

The influence of the contact structure on the optical and MO properties of the isolator was estimated through simulation of an isolator benchmark example with each of the five contact structures of table 1. Calculations have been done with the mode solver CAMFR [3] extended with a perturbation-based algorithm for MO waveguide calculation [4]. The experimental values of the optical and $\mathrm{MO}$ parameters of the ferromagnetic metal $\mathrm{Co}_{50} \mathrm{Fe}_{50}$ served as input for these simulations. The important figure of merit for this type of device is the ratio between the non-reciprocal loss and the remaining loss in the forward propagation direction, the 'isolation-to-loss ratio'. The outcome of these simulations is plotted in figure 2. It can immediately be concluded that the absorption in the ternary $\mathrm{In}_{0.53} \mathrm{Ga}_{0.47} \mathrm{As}$ contact layer seriously decreases the performance of the isolator, hence from (magneto)optical point of view it is best to use a purely quaternary $\mathrm{In}_{0.81} \mathrm{Ga}_{0.19} \mathrm{As}_{0.41} \mathrm{P}_{0.59}$ contact. Furthermore, the thickness of the quaternary contact layer must be large enough for the isolation-to-loss ratio to be maximal. The explanation for this is that the phase of the transverse electric field component at the metal-semiconductor interface is then better matched to the complex argument of the off-diagonal elements of the permittivity tensor of $\mathrm{Co}_{50} \mathrm{Fe}_{50}$ [5]. 
For the extraction of the electrical quality of the five contact structures, cross-bridge Kelvin resistors [6] have been fabricated. Be p $\mathrm{p}^{++}$-doped $\mathrm{In}_{0.81} \mathrm{Ga}_{0.19} \mathrm{As}_{0.41} \mathrm{P}_{0.59}\left(\mathrm{~N}_{\mathrm{Be}}=2 \times 10^{19} \mathrm{~cm}^{-3}\right)$ and $\operatorname{In}_{0.53} \mathrm{Ga}_{0.47} \mathrm{As}\left(\mathrm{N}_{\mathrm{Be}}=3 \times 10^{19} \mathrm{~cm}^{-3}\right)$ layers with gas source molecular beam epitaxy (GSMBE) on an InP substrate. Whereas such high dopant levels are standard for $\mathrm{In}_{0.53} \mathrm{Ga}_{0.47} \mathrm{As}$, this is not the case for $\mathrm{In}_{0.81} \mathrm{Ga}_{0.19} \mathrm{As}_{0.41} \mathrm{P}_{0.59}$, but we succeeded by growing the quaternary material at low temperature $\left(\mathrm{T}_{\mathrm{s}}=460^{\circ} \mathrm{C}\right)$. A $50 \mathrm{~nm}$ thick $\mathrm{Co}_{50} \mathrm{Fe}_{50} \mathrm{MO}$ metal layer was then sputtered and topped with a Ti/Au protective bilayer $(40 \mathrm{~nm} / 150 \mathrm{~nm})$. Rapid thermal processing (RTP), which is known to improve the contact quality [7], was carried out at temperatures between $250^{\circ} \mathrm{C}$ and $450^{\circ} \mathrm{C}$, in a forming gas $\left(\mathrm{N}_{2}: \mathrm{H}_{2}\right)$ atmosphere (duration, 30 seconds). With the aid of a MATLAB algorithm [6] we were able to extract the contact resistivity very accurately. As is illustrated in figure 3 a purely quaternary contact (Q1 and Q2) has a too high value of the contact resistivity, but the contact quality of a standard ternary contact can be well approached by topping a $100 \mathrm{~nm}$ $\mathrm{In}_{0.81} \mathrm{Ga}_{0.19} \mathrm{As}_{0.41} \mathrm{P}_{0.59}$ layer with a $15 \mathrm{~nm} \mathrm{In}_{0.53} \mathrm{Ga}_{0.47} \mathrm{As}$ layer (H1 scheme) and performing RTP at $350^{\circ} \mathrm{C}$. Now, as the (magneto-)optical performance of this $\mathrm{H} 1$ scheme is much better than that of a standard structure (figure 2), it can be concluded that the hybrid $\mathrm{H} 1$ contact scheme is the preferred ohmic electrical contact for the amplifying waveguide optical isolator. With that, we have solved one of the important issues towards an integratable optical isolator.

\section{Acknowledgement}

This research has been carried out in the framework of the European Union IST research program ISOLASER.

Figures

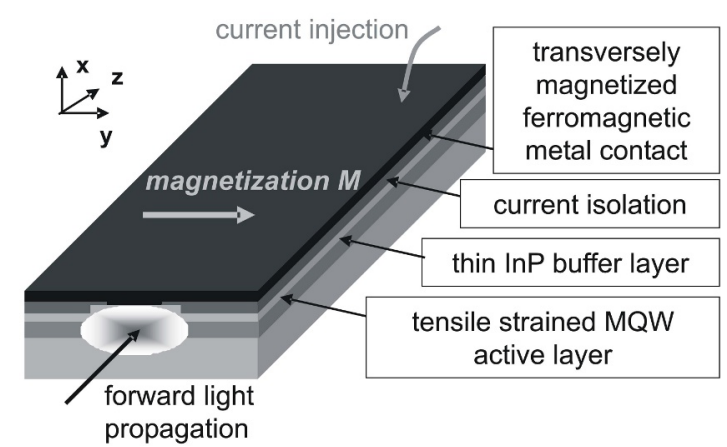

Fig. 1: Lay-out of the amplifying waveguide optical isolator.

\begin{tabular}{cccc}
\hline label & composition & $\begin{array}{c}\text { thickness } \\
(\mathrm{nm})\end{array}$ & $\begin{array}{c}\text { Be dopant } \\
\text { concentration }\left(\mathrm{cm}^{-3}\right)\end{array}$ \\
\hline $\mathrm{T}$ & $\mathrm{In}_{0.53} \mathrm{Ga}_{0.47} \mathrm{As}$ & 100 & $3 \times 10^{19}$ \\
\hline $\mathrm{H} 1$ & $\begin{array}{c}\mathrm{In}_{0.81} \mathrm{Ga}_{0.19} \mathrm{As}_{0.41} \mathrm{P}_{0.59} \\
/ \mathrm{In}_{0.53} \mathrm{Ga}_{0.47} \mathrm{As}\end{array}$ & $100 / 15$ & $2 \times 10^{19} / 3 \times 10^{19}$ \\
\hline $\mathrm{H} 2$ & $\begin{array}{c}\mathrm{In}_{0.81} \mathrm{Ga}_{0.19} \mathrm{As}_{0.41} \mathrm{P}_{0.59} \\
/ \mathrm{In}_{0.53} \mathrm{Ga}_{0.47} \mathrm{As}\end{array}$ & $100 / 5$ & $2 \times 10^{19} / 3 \times 10^{19}$ \\
\hline $\mathrm{Q} 1$ & $\mathrm{In}_{0.81} \mathrm{Ga}_{0.19} \mathrm{As}_{0.41} \mathrm{P}_{0.59}$ & 100 & $2 \times 10^{19}$ \\
\hline $\mathrm{Q} 2$ & $\mathrm{In}_{0.81} \mathrm{Ga}_{0.19} \mathrm{As}_{0.41} \mathrm{P}_{0.59}$ & 50 & $2 \times 10^{19}$ \\
\hline
\end{tabular}

Table 1: Specifications of the five semiconductor contact structures.
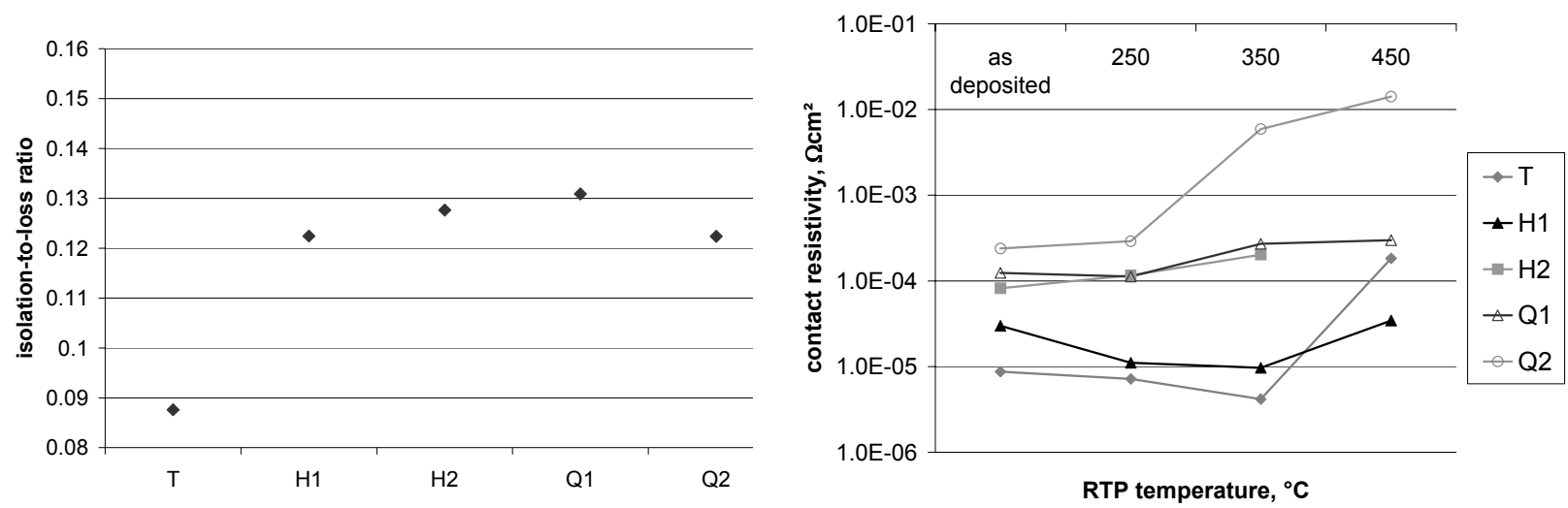

Fig. 2: Simulated isolation-to-loss ratio for the five contact structures.

Fig. 3: Extracted contact resistivity for different RTP temperatures, for all five contact structures.

\section{References}

[1] M. Vanwolleghem, W. Van Parys, D. Van Thourhout, R. Baets, F. Lelarge, O. Gauthier-Lafaye, B. Thedrez, R. Wirix-Speetjens, and L. Lagae, Appl. Phys. Lett. 85, 3980 (2004).

[2] H. Shimizu, and Y. Nakano, in Proceedings of the Optical Fiber Communication Conference, Anaheim, California, 6-11 March 2005 , PDP18.

[3] P. Bienstman, and R. Baets, Opt. and Quantum Electron. 33, 327 (2001).

[4] K. Postava, M. Vanwolleghem, D. Van Thourhout, R. Baets, S. Visnovský, P. Beauvillain, J. Pistora, J.Opt. Soc. Am. B 22, 261 (2005).

[5] M. Vanwolleghem, W. Van Parys, P. Gogol, P. Beauvillain, and R. Baets, 'Design and optimization of a monolithically integrated InP-based optical waveguide isolator', submitted to JOSA B.

[6] W.M. Loh, S.E. Swirhun, T.A. Schreyer, R.M. Swanson, and K.C. Saraswat, IEEE Trans. on Electron. Devices 34, $512-523$ (1987).

[7] A. Katz, P.M. Thomas, S.N.G. Chu, W.C. Dautremont-Smith, R.G. Sobers, and S.G. Napholtz, J. Appl. Phys. 67, 884-889 (1990). 


\section{IEEE LEOS Annual Meeting Conference Proceedings}

\section{Copyright and Reprint Permission}

() 2006 IEEE. Personal use of this material is permitted. However, permission to reprint/republish this material for advertising or promotional purposes or for creating new collective works for resale or redistribution to servers or lists, or to reuse any copyrighted component of this work in other works must be obtained from the IEEE.

\section{IEEE Catalog Number: 06CH37736C} ISBN: 0-7803-9556-5

This product was produced for the 2006 IEEE LEOS Annual Meeting Conference by Omnipress. Duplication of this product and its content in print or digital form for the purpose of sharing with others is prohibited without permission from the 2006 IEEE LEOS Annual Meeting Conference.

In no event will Omnipress or its suppliers be liable for any consequential or incidental damages to your hardware or other software resulting from the installation and/or use of this product.

No part of the Omni EZ-Setup ${ }^{\mathrm{TM}}$ software and product "Help" files may be reproduced or used without written permission from Omnipress. (02006 Omnipress - All rights reserved.

For technical issues, contact:

PRODUCED BY

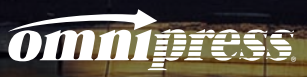

\section{Omnipress Technical Support}

Phone: 608-246-2600

Fax: 608-246-4237

E-mail: digital@omnipress.com

\section{Main Menu}




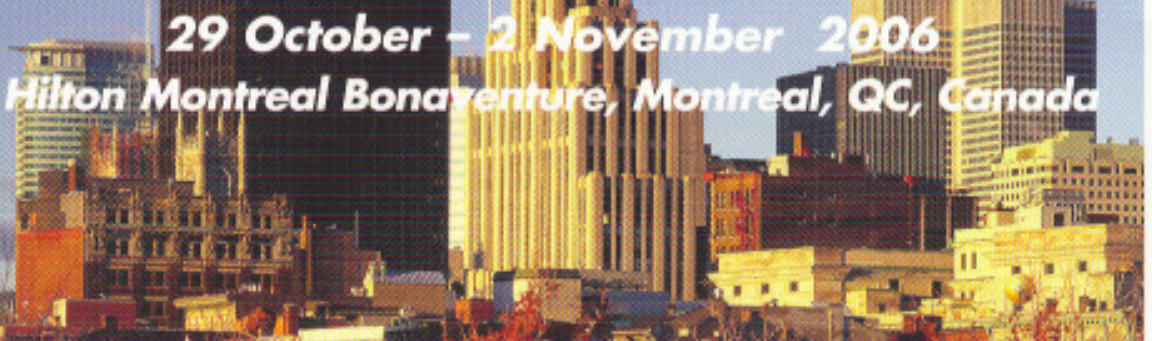

\section{IEEE LEOS Annual Meeting \\ - Conference hoceedings

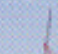

29 October - PVimber

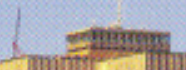

